\title{
Dimensions and determinants of quality of life among senior citizens of Lucknow, India
}

Background: In India, there is low awareness about special needs of the elderly and their care takers. We are yet to understand the basics of elderly care (physical and mental health, psychological and social support). Objectives: (1) To study the dimensions of quality of life (QOL) of elderly people living in community and in old age homes (OAHs). (2) To determine the predictors of $\mathrm{QOL}$ among elderly people. Materials and Methods: A cross-sectional descriptive study was undertaken with elderly people (age $\geq 60$ years) from the community and from OAHs residing in Lucknow city, India were the participants. Multistage sampling technique was used in the general population and all the elderly people living in OAHs were included in the study. 141 elderly people from community and 101 elderly people from OAHs were studied after taking oral consent and scoring $\geq 20$ on Mini Mental State Examination instrument. Instrument used for assessing $\mathrm{QOL}$ was World Health Organization QOL-bref. Tools used to screen out anxiety and depression cases were Geriatric Depression Scale - Hindi version and Hamilton Anxiety Rating Scale. Results: The mean scores of QOL domains were higher among married elderly people, elderly people without mental health problem and elderly people without psychosocial issue/s. Similarly, it was higher among elderly people living in the community and paid $\mathrm{OAHs}$ than in free OAHs. Conclusion: $\mathrm{QOL}$ of elderly residing in paid OAHs were similar to those from the community. Financial dependency was the strongest predictor of QOL.

Abhishek Gupta, Uday Mohan', Sarvada C. Tiwari², Shivendra K. Singh', Vijay K. Singh ${ }^{1}$

Department of Community Medicine, Navodaya Medical College, Raichur, Karnataka,

${ }^{1}$ Departments of Community Medicine and Public Health and ${ }^{2}$ Geriatric Mental Health,

K. G. Medical University,

Uttar Pradesh, Lucknow, India

Address for the Correspondence:

Dr. Abhishek Gupta,

362-H, Patel Nagar, Indira Nagar, Lucknow - 226 016, Uttar Pradesh,

India.

E-mail: ab23kgmc@gmail.com

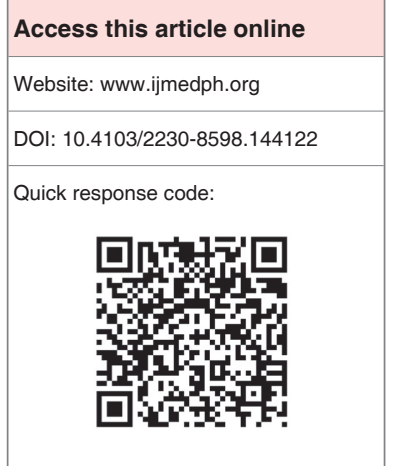

Key words: Elderly people, old age home, quality of life, World Health Organization quality of life-bref

\section{INTRODUCTION}

Quality of life (QOL) of elderly people is becoming even more relevant with demographic shift happening toward an ageing society. ${ }^{[1]}$ There are indications that concerns related to QOL in elderly people are different from that of the general population. ${ }^{[2]}$ Furthermore, among the elderly, there is variation between those living in old age homes $(\mathrm{OAHs})$ and those living in the general population. In India, there is low awareness about special needs of the elderly and care takers are yet to understand the basics of elderly care (physical and mental health, psychological and social support). ${ }^{\left[{ }^{[2]}\right.}$ The researcher was hence interested in studying QOL of the elderly people and factors affecting it in Lucknow, India and believes that the results obtained will help in planning and policy making with regards to elderly care in the future.

\section{Objectives}

1. To study the dimensions of QOL of elderly people living in community and in OAHs

2. To determine the predictors of QOL among elderly people.

\section{MATERIALS AND METHODS}

It was a cross-sectional descriptive study. Participants were elderly people ${ }^{[3]}$ enrolled in OAHs and from the general population residing in Lucknow city. The study covered two sets of the elderly population and for both groups inclusion criteria were: Age $\geq 60$ years, residing in community or OAHs for $\geq 6$ months (can be permanent or temporary resident) and scored $\geq 20$ on Mini Mental State Examination (MMSE) instrument. ${ }^{[6,7]}$ Study period was from May 2012 to May 2013. There were 
four OAHs in Lucknow, and all of them were situated in the urban area. Elderly people living in OAHs were approached after taking permission from in-charges of these OAHs and verbal consent from subjects regarding study. All the elderly people living in OAHs gave consent to participate in the study, out of which six were excluded because they were unable to get a score $\geq 20$ on MMSE instrument making a total 101 subjects in the study.

In the community, sample size was 141 using prevalence of psychosocial problem in elderly people as $42 \%{ }^{[4]}$ and 1.5 design effect. Multistage sampling technique was used to obtain the requisite number of respondents from the community. In the first stage out of 9 Legislative Constituencies (LC) of Lucknow district 5 LC representing urban population, was included in the study. In second stage list of polling stations was obtained from the website of Chief Electoral Officer, Uttar Pradesh ${ }^{[5]}$ for each LC. One polling station was selected from each LC by simple random sampling technique. In the third stage from each selected polling station, list of all the voters with their age, sex and address were taken from the website of Chief Electoral Officer, Uttar Pradesh. Respondents of $\geq 60$ years were shortlisted, and a separate list of elderly people was made and five people were selected by simple random sampling technique from selected polling station. Of these five selected subjects $1^{\text {st }}$ was approached, if individual had given consent and scored $\geq 20$ on MMSE instrument then further interview was continued otherwise next individual was approached and so on. If $1^{\text {st }}$ had given consent and scored $\geq 20$ on MMSE rest were not approached for that poll station. Thus, only one person was selected from each polling station. Total 204 subjects were approached in community out of which 49 refused to participate in the study (out of 49 refusals 40 refusals was by their children or by care takers due to their personal reasons and only nine refusals were by subject itself), and 14 subjects were excluded because they were unable to get a score $\geq 20$ on MMSE instrument. Thus, a total of 141 subjects were finally included in the study.

Tools used to screen anxiety and depression cases were Geriatric Depression Scale — Hindi version (GDS-H),${ }^{[8]}$ Hamilton Anxiety Rating Scale (HAM-A). ${ }^{[9,10]}$ To become conversant with the tools, sign/symptoms of depression, anxiety and to understand the eligibility criteria of the study population regarding the application of the tools the principle investigator underwent a training of 20 days in Department of Geriatric and Mental Health. Subjects who had chief complaints of anxiety and depression were the ones eligible for tool application. Thus in all GDS-H or HAM-A was applied on 110 subjects.

Tool used to assess QOL of elderly people was World Health Organization QOL (WHOQOL)-bref. ${ }^{[11-15]}$ Cognitive function of an individual is of utmost importance as the individuals below a certain level cannot respond to questions being put forward to him. In order to obtain this level, MMSE instrument was applied to each respondent.

Subjects with other systemic chronic/serious/long-term illness were considered as diagnosed cases if they were able to show outpatient department slip of at least secondary level government health facility or prescription from specialist private practitioner or if they were showing investigation reports and drugs that they were using regularly with clinical sign and symptoms.

\section{Tools of data collection}

1. Mini Mental State Examination: Translated Hindi version of MMSE instrument ${ }^{[6,7]}$ was used in the study. The MMSE has a maximum score of 30 points. Score $<20$ on MMSE has increased odds of dementia so was used as a cut-off point.

2. Geriatric Depression Scale Hindi version: GDS- $\mathrm{H}^{[8]}$ was used for the assessment of depression. There are 30 depressive symptoms, each of which is scored as 1 if present and 0 if absent. A higher score, therefore, reflects a greater number of symptoms. On summing the scores of different question for a total score of 30 , score $\geq 22$ were considered as positive for depression. Cut-off point used by Ganguli et al..$^{[8]}$ was tested in a pilot study and was correlated clinically in Department of Geriatric Mental Health, KGMU Lucknow.

3. Hamilton-Anxiety Rating Scale: HAM-A ${ }^{[9,10]}$ was used for the assessment of anxiety which consist of 14 items. Each item is scored on a 5 -point scale, ranging from $0=$ not present to $4=$ severe. The anxiety score ranges from 0 to 56 . The seven psychic anxiety items elicit a psychic anxiety score that ranges from 0 to 28. The remaining seven items yield a somatic anxiety score that also ranges from 0 to 28 . A score $\geq 18$ is considered to be positive for anxiety.

4. World Health Organization QOL-bref: The WHOQOLbref ${ }^{[11-15]}$ is a self-assessment instrument for assessment of QOL. Hindi version was used in the study it consists of 26 questions, divided into four domains. The questions of the different sections of the instrument use the Likert response scale. The scores of all four domains were converted into Sten scores which lie between 0 and 100 (the higher the score, the better is the supposed QOL of elderly people for that domain).

5. Socioeconomic Status (SES): SES was classified on the basis of "a scale for the assessment of SES." "[16] There are seven aspects investigated in the scale for determining the SES of a family or individual. These aspects are:

1. House,

2. Material possessions,

3. Education,

4. Occupation,

5. Economic profile,

6. Possessed land/house cost and

7. Social profile. On SES scale maximum score which can be obtained is 70 .

The scores are categorized into five SES classes that is, scores 0-15: Lower class, scores 15-30: Lower middle class, score 30-45: Middle class, score 45-60: Upper middle class, score 60-70 upper class. For SES of individual (elderly) was taken in both groups. 
The schedule was pretested on elderly people of $\geq 60$ years residing in the community of Lucknow city. Relevant modifications were made in the schedule to overcome the difficulties faced during pretesting.

Descriptive statistics such as mean, standard deviation for continuous variables and frequency percentage for categorical variables were determined. Student's $t$-test for independent sample, oneway analysis of variance with Games-Howell post hoc test (when appropriate) was used to show the relation between independent and dependent variables. The level of significance was set at $P<0.05$. SPSS 19 was used for analysis.

\section{Observations}

In study population among elderly $70.9 \%$ were males, and $29.1 \%$ were females while in OAHs overall $53.5 \%$ were males and $46.5 \%$ were females. Among the elderly living in the community, $80.9 \%$ were Hindus followed by $11.3 \%$ Muslims. Among OAH's elderly, 99.0\% were Hindu. In the study population, $78.7 \%$ elderly were married and $18.4 \%$ who were widow/widower. In OAHs, a majority of $54.5 \%$ were widow/widower and $31.7 \%$ who were married. In free OAHs majority of elderly were illiterate (51.4\%) followed by primary pass $(28.6 \%)$ and in paid OAHs a maximum of $40.9 \%$ were graduate/diploma followed by postgraduate and above (33.3\%). In the community, a maximum of $44.7 \%$ elderly were in class III of SES. While in free OAHs a maximum of $71.4 \%$ were belonged to class $\mathrm{V}$ and in paid $\mathrm{OAHs}$ distribution a maximum of $60.6 \%$ elderly were in class III [Table 1].

Statistically, significant difference was found in the mean scores of (i) physical health $(P<0.001)$, (ii) psychological health $(P=0.011)$ and (iii) environmental health $(P=0.03)$ between subjects with one or more health related issue/s and those without health related issue/s. The mean QOL scores of these domains were higher among elderly people without health related issue/s. In the case of social relationship difference in mean scores between two groups was not significant statistically $(P=0.19)$. The mean score for QOL scores of these domains is higher among married people. The mean scores of these domains was higher among subjects without mental health problem/s. Similarly, mean QOL scores of these domains was found to be higher among elderly people without psychosocial issue/s [Table 2].

There were statistically significant differences among the mean scores of physical health $(P<0.001)$, psychological health $(P<$ $0.001)$, environmental health $(P<0.001)$ for the subjects living in community and free OAHs. Statistically, significant difference was

\begin{tabular}{|c|c|c|c|c|c|c|c|c|}
\hline \multirow[t]{3}{*}{ Characteristics } & \multirow{2}{*}{\multicolumn{2}{|c|}{$\begin{array}{c}\text { Community } \\
(n=141)\end{array}$}} & \multicolumn{6}{|c|}{ Old age homes } \\
\hline & & & \multicolumn{2}{|c|}{ Free $(n=35)$} & \multicolumn{2}{|c|}{ Paid $(n=66)$} & \multicolumn{2}{|c|}{ Total $(n=101)$} \\
\hline & $n$ & $\%$ & $n$ & $\%$ & $n$ & $\%$ & $n$ & $\%$ \\
\hline \multicolumn{9}{|l|}{ Age group (years) } \\
\hline $60-<70$ & 82 & 58.2 & 11 & 31.4 & 18 & 27.3 & 29 & 28.7 \\
\hline $70-<80$ & 46 & 32.6 & 16 & 45.7 & 22 & 33.3 & 38 & 37.6 \\
\hline$\geq 80$ & 13 & 9.2 & 08 & 22.9 & 26 & 39.4 & 34 & 33.7 \\
\hline \multicolumn{9}{|l|}{ Sex } \\
\hline Male & 100 & 70.9 & 17 & 48.6 & 37 & 56.1 & 54 & 53.5 \\
\hline Female & 41 & 29.1 & 18 & 51.4 & 29 & 43.9 & 47 & 46.5 \\
\hline \multicolumn{9}{|l|}{ Religion } \\
\hline Hindu & 114 & 80.9 & 35 & 100.0 & 65 & 98.5 & 100 & 99.0 \\
\hline Muslim & 16 & 11.3 & 00 & 00 & 01 & 1.5 & 01 & 1.0 \\
\hline Sikh & 11 & 7.8 & 00 & 00 & 00 & 00 & 00 & 00 \\
\hline \multicolumn{9}{|l|}{ Marital status } \\
\hline Unmarried & 02 & 1.4 & 03 & 8.6 & 03 & 4.5 & 06 & 5.9 \\
\hline Married & 111 & 78.7 & 09 & 25.7 & 23 & 34.8 & 32 & 31.7 \\
\hline Widow/widower & 26 & 18.4 & 20 & 57.1 & 35 & 53.0 & 55 & 54.5 \\
\hline Divorce/separated & 02 & 1.4 & 03 & 8.6 & 05 & 7.6 & 08 & 7.9 \\
\hline \multicolumn{9}{|l|}{ Educational profile } \\
\hline Illiterate & 23 & 16.3 & 18 & 51.4 & 04 & 6.1 & 22 & 21.8 \\
\hline Primary pass & 13 & 9.2 & 10 & 28.6 & 05 & 7.6 & 15 & 14.9 \\
\hline $10^{\text {th }}$ pass & 40 & 28.4 & 04 & 11.4 & 08 & 12.1 & 12 & 11.9 \\
\hline Graduate/diploma & 35 & 24.8 & 02 & 5.7 & 27 & 40.9 & 29 & 28.7 \\
\hline Postgraduate and above & 30 & 21.3 & 01 & 2.9 & 22 & 33.3 & 23 & 22.8 \\
\hline \multicolumn{9}{|l|}{ Socioeconomic status ${ }^{@}$} \\
\hline Class I & 06 & 4.3 & 00 & 00 & 01 & 1.5 & 01 & 1.0 \\
\hline Class II & 39 & 27.7 & 00 & 00 & 06 & 9.1 & 06 & 5.9 \\
\hline Class III & 63 & 44.7 & 00 & 00 & 40 & 60.6 & 40 & 39.6 \\
\hline Class IV & 32 & 22.7 & 10 & 28.6 & 16 & 24.2 & 26 & 25.7 \\
\hline Class V & 01 & 0.7 & 25 & 71.4 & 03 & 4.5 & 28 & 27.7 \\
\hline
\end{tabular}




\begin{tabular}{|c|c|c|c|c|}
\hline \multirow[t]{3}{*}{ Characteristics } & \multicolumn{4}{|c|}{ Domains of QOL } \\
\hline & Physical health & Psychological health & Social relationship & Environmental health \\
\hline & Mean score \pm SD & Mean score \pm SD & Mean score \pm SD & Mean score \pm SD \\
\hline \multicolumn{5}{|c|}{ Health related issue/s } \\
\hline Present & $46.21 \pm 17.87$ & $44.24 \pm 22.13$ & $42.39 \pm 21.32^{\#}$ & $44.18 \pm 21.63$ \\
\hline Absent & $58.95 \pm 15.72$ & $51.13 \pm 18.05$ & $46.32 \pm 21.89^{\#}$ & $49.87 \pm 18.00$ \\
\hline \multicolumn{5}{|l|}{ Marital status } \\
\hline Single* & $43.79 \pm 16.67$ & $39.09 \pm 20.88$ & $40.27 \pm 20.64$ & $39.96 \pm 22.57$ \\
\hline Married & $54.74 \pm 17.89$ & $51.51 \pm 19.83$ & $45.97 \pm 21.90$ & $50.17 \pm 18.19$ \\
\hline \multicolumn{5}{|c|}{ Psycho-social issue/s } \\
\hline Present & $47.02 \pm 17.35$ & $42.27 \pm 20.66$ & $41.36 \pm 21.26$ & $43.27 \pm 20.56$ \\
\hline Absent & $62.71 \pm 15.94$ & $62.41 \pm 14.29$ & $52.41 \pm 20.48$ & $56.43 \pm 17.73$ \\
\hline \multicolumn{5}{|c|}{ Mental health problem } \\
\hline Present & $44.23 \pm 17.73$ & $39.23 \pm 19.80$ & $38.04 \pm 19.24$ & $42.27 \pm 19.40$ \\
\hline Absent & $53.90 \pm 17.53$ & $50.77 \pm 20.77$ & $47.01 \pm 22.19$ & $48.24 \pm 21.16$ \\
\hline
\end{tabular}

also observed between subjects living in free OAHs and those living in paid type of OAH's for physical health $(P<0.001)$, psychological health $(P<0.001)$ and environmental health $(P<0.001)$. The difference between the mean score of social relationship domain of QOL was statistically significant between subjects living in community and free type of OAH's only $(P=0.007)$. Difference in mean scores between community and paid OAHs was statistically insignificant for all four domains of QOL [Table 3].

Education, financial dependency, SES, feeling of loneliness, mental health problem/s, and health-related issue/s can predict the QOL of the elderly people. These factors predict $53.7 \%$ of the variability in the prediction of QOL of elderly people. The strongest factor that influenced the QOL was financial dependency. Variables such as age, sex, marital status, living status, no male child, residential status, feeling of neglect and psychosocial issues/s were significant when taken individually to predict the QOL [Table 4].

\section{DISCUSSION}

In the study population residing in the community it was found that the number of male respondents were much higher than female elderly, this difference was mainly because males were more interested to participate in the study when compared to females. Being a male dominating society, there were lesser refusals on the male side. The reason for a total absence of Sikhs and only a minor population of Muslims in the OAHs may be due to joint family system being still present in these religions.

Statistically significant differences were also observed between mean scores of physical health $(P<0.001)$, psychological health $(P<0.001)$, social relationship $(P=0.041)$ and environmental health $(P<0.001)$ between single and married elderly people. The mean QOL scores of these domains is higher among married elderly people. This differs from the findings of a study in Wardha, India ${ }^{[17]}$ and a study on the same variable, the differences may be attributed to small sample size (70 samples and hospital based data), sex composition reverse to this study..$^{[18]}$

\begin{tabular}{|c|c|c|c|}
\hline \multirow{3}{*}{$\begin{array}{l}\text { Domains of QOL } \\
(n=242)\end{array}$} & \multirow{3}{*}{$\begin{array}{c}\begin{array}{c}\text { Community } \\
(n=141)\end{array} \\
\text { Mean } \\
\text { score } \pm \text { SD }\end{array}$} & \multicolumn{2}{|c|}{ Old age homes } \\
\hline & & Free $(n=35)$ & Paid $(n=66)$ \\
\hline & & $\begin{array}{c}\text { Mean } \\
\text { score } \pm \text { SD }\end{array}$ & $\begin{array}{c}\text { Mean } \\
\text { score } \pm \text { SD }\end{array}$ \\
\hline Physical health & $54.35 \pm 18.07^{a}$ & $35.30 \pm 11.90^{\mathrm{a}, \mathrm{b}}$ & $49.45 \pm 17.06^{b}$ \\
\hline Psychological health & $50.85 \pm 20.33^{a}$ & $23.69 \pm 14.94^{a, b}$ & $49.05 \pm 17.89^{b}$ \\
\hline Social relationship & $46.42 \pm 21.062^{\mathrm{a}}$ & $32.50 \pm 23.76^{a}$ & $43.62 \pm 19.62$ \\
\hline Environmental health & $49.75 \pm 18.54^{a}$ & $20.00 \pm 11.22^{\mathrm{a}, \mathrm{b}}$ & $51.75 \pm 18.74^{b}$ \\
\hline
\end{tabular}

a,bStatistically significant $(P<0.05), \mathrm{SD}=$ Standard deviation, $\mathrm{QOL}=$ Quality of life

Results of this study showed that statistically significant differences were observed between community and free OAHs for physical health $(P<0.001)$, psychological health $(P<0.001)$, environmental health $(P<0.001)$ domains of QOL. Similarly, statistically significant difference was also observed between subjects living in free OAHs and those living in paid type of OAH's for above mentioned domains $(P<0.001$ in all three domains). This may be due poor infrastructure and poor living standard in free OAHs. But statistically significant difference was not observed between community and paid OAH's $(P>0.05)$. This may be due to better infrastructure and facilities in paid OAHs.

Financial dependency, SES and health related issue/s can predict the QOL of the elderly people. These factors predict $53.7 \%$ of the variability in the prediction of QOL of elderly people. These findings were similar to the findings of other studies. ${ }^{[19,20]}$

\section{CONCLUSION}

Quality of life was better among married elderly people than single elderly people. QOL was better among elderly people without health related issue/s, without psychosocial issue/s and without mental health problem/s. QOL of elderly people was significantly higher among paid OAH's residents than among free OAH's residents $(P<0.001)$. Similarly, it was significantly higher among community residents than among free OAH residents $(P<0.001)$. QOL 


\begin{tabular}{|c|c|c|c|c|c|c|}
\hline \multirow[t]{2}{*}{ Variables $(n=242)$} & \multicolumn{2}{|c|}{ Unstandardized coefficient } & \multirow{2}{*}{$\frac{\text { Standardized coefficient }}{\beta}$} & \multirow[t]{2}{*}{$P$} & \multicolumn{2}{|c|}{$\mathrm{Cl}(95 \%)$} \\
\hline & B & SE & & & Lower & Upper \\
\hline Education & 1.33 & 0.38 & 0.210 & 0.001 & 0.58 & 2.08 \\
\hline Financial dependency & -6.14 & 1.21 & 0.278 & 0.000 & -8.53 & -3.74 \\
\hline Socioeconomic status & -5.03 & 1.08 & -0.279 & 0.000 & -7.17 & -2.89 \\
\hline Feeling of loneliness & -5.53 & 1.95 & -0.132 & 0.005 & -9.37 & -1.68 \\
\hline Mental health problem/s & -4.59 & 1.68 & -0.125 & 0.007 & -7.89 & -1.28 \\
\hline Health related issue/s & -3.95 & 1.74 & -0.104 & 0.024 & -7.37 & -0.52 \\
\hline
\end{tabular}

$\mathrm{B}_{\mathrm{o}}=73.99, R^{2}=0.537, \mathrm{SE}=$ Standard error, $\mathrm{Cl}=$ Confidence interval

among resident of paid OAHs was similar to community residents. Education, financial dependency, SES, feeling of loneliness, mental health problem/s, and health related issue/s were important predict the QOL of the elderly people. Financial dependency was the most important predictor of QOL.

\section{Recommendations}

1. Government sponsored or public-private partnership based OAHs with better infrastructure and facilities should be established at district level especially for economically vulnerable sections of society

2. Revision old age pension based on government norms or based on inflation should be emphasized

3. The study recommends the need to conduct various studies in similar settings involving certain care interventions and their impact on elderly health.

\section{ACKNOWLEDGMENT}

I am thankful to Mr. Rakesh Kumar Tripathi, Dr. Nisha M. Pandey, Department of Geriatric Mental Health, Er. Manish Manar, Department of Community Medicine and Public Health, King George's Medical University Lucknow, Dr. Rahul Chaturvedi, Dr Ashish Chauhan, Dr. Ashish Srivastava and my dear juniors for their constant encouragement and motivation.

\section{REFERENCES}

1. Gehner M. Active healthy ageing: The global perspective. Health SouthEast Asia 2012;5:8-9. Available from: http://www.searo.who.int/LinkFiles/ WHD-12_hisea.pdf. [Last accessed 2012 Dec 23]

2. Myanmar Country Report to the $5^{\text {th }}$ ASEAN \& Japan high level officials meeting on caring societies: Collaboration of Social Welfare and Health Services and Development of Human Resources and Community, Community Services for the Elderly 2007. Available from: http://www. mhlw.go.jp/bunya/kokusaigyomu/asean/asean/kokusai/siryou/dl/h19_ myanmar.pdf. [Last accessed on 2014 Jan 10].

3. Central Statistics Office Ministry of Statistics and Programme Implementation, Government of India. Situation Analysis of the Elderly in India, New Delhi; June, 2011. Available from: http://www.mospi.nic.in/ mospi_new/upload/elderly_in_india.pdf. [Last accessed on 2014 Mar 12].

4. Prakash R, Chaudhary SK, Singh UC. A study of morbidity pattern among geriatric population in an urban area of Udaipur, Rajasthan. Indian J Community Med 2004;29:35.

5. Chief Electoral Officer, Uttar Pradesh. Available from: http://www. ceouttarpradesh.nic.in. [Last accessed on 2012 Jan 13].
6. Folstein MF, Folstein SE, McHugh PR. Mini-mental state. A practical method for grading the cognitive state of patients for the clinician. J Psychiatr Res 1975;12:189-98.

7. Crum RM, Anthony JC, Bassett SS, Folstein MF. Population-based norms for the Mini-Mental State Examination by age and educational level. JAMA 1993;269:2386-91.

8. Ganguli M, Dube S, Johnston JM, Pandav R, Chandra V, Dodge HH. Depressive symptoms, cognitive impairment and functional impairment in a rural elderly population in India: A Hindi version of the geriatric depression scale (GDS-H). Int J Geriatr Psychiatry 1999;14:807-20.

9. Hamilton $\mathrm{M}$. The assessment of anxiety states by rating. $\mathrm{Br} \mathrm{J} \mathrm{Med} \mathrm{Psychol}$ 1959;32:50-5.

10. Maier W, Buller R, Philipp M, Heuser I. The hamilton anxiety scale: Reliability, validity and sensitivity to change in anxiety and depressive disorders. J Affect Disord 1988;14:61-8.

11. The World Health Organization Quality of Life Assessment (WHOQOL): Development and general psychometric properties. Soc Sci Med 1998;46:1569-85.

12. Development of the World Health Organization WHOQOL-BREF quality of life assessment. The WHOQOL Group. Psychol Med 1998;28:551.

13. Power $M$, Harper A, Bullinger M. The World Health Organization WHOQOL-100: Tests of the universality of Quality of Life in 15 different cultural groups worldwide. Health Psychol 1999;18:495-505.

14. Skevington SM, Lotfy M, O'Connell KA, WHOQOL Group. The World Health Organization's WHOQOL-BREF quality of life assessment: Psychometric properties and results of the international field trial. A report from the WHOQOL group. Qual Life Res 2004;13:299-310.

15. Saxena S, Chandiramani K, Bhargava R. WHOQOL-Hindi:Aquestionnaire for assessing quality of life in health care settings in India. World Health Organization Quality of Life. Natl Med J India 1998;11:160-5.

16. Tiwari SC, Kumar A, Kumar A. Development \&amp; standardization of a scale to measure socio-economic status in urban \&amp; rural communities in India. Indian J Med Res 2005;122:309-14.

17. Mudey A, Ambekar S, Goyal RC, Agarekar S, Wagh VV. Assessment of quality of life among rural and urban elderly population of Wardha District, Maharashtra, India. Ethno Med 2011;5:89-93.

18. Barua A, Mangesh R, Harsha Kumar HN, Mathew S. A cross-sectional study on quality of life in geriatric population. Indian J Community Med 2007;32:146-7.

19. Naing MM, Nanthamongkolchai S, Munsawaengsub C. Quality of life of the elderly people in Einme township Irrawaddy division, Myanmar. Asia J Public Health 2010;1:4-10.

20. Gureje O, Kola L, Afolabi E, Olley BO. Determinants of quality of life of elderly Nigerians: Results from the Ibadan study of ageing. Afr J Med Med Sci 2008;37:239-47.

How to cite this article: Gupta A, Mohan U, Tiwari SC, Singh SK, Singh VK. Dimensions and determinants of quality of life among senior citizens of Lucknow, India. Int J Med Public Health 2014;4:477-81.

Source of Support: Nil, Conflict of Interest: None declared. 